\title{
Small Vertebrate Colonisers of Mine Site Rehabilitated Waste Dumps in the Goldfields of Western Australia
}

\author{
G.G. Thompson Centre for Ecosystem Management, Edith Cowan University, Australia
}

S.A. Thompson ATA Environmental, Australia

\section{INTRODUCTION}

Mine site waste dumps pass through various stages as they progress towards the development of mature ecosystems. The ultimate ecosystem on a rehabilitated waste dump is largely determined by the soils and vegetation, and connections with the adjacent habitats that enable invertebrates and vertebrates to move into this area. For some mine sites, the primary objective is to create near-natural, self-sustaining functional ecosystems, others settle for lesser outcomes. To achieve a near-natural, self-sustaining, functional ecosystem is not easy and a lofty objective because of the difficulty in creating the weathered topography and soils of the region, and creating vegetation assemblages of natural ecosystems. Most often waste dumps are huge structures that rise above the existing soil profile, are filled with mining waste in the sequence that it is extracted from the mine, and have a top soil capping that is ripped to reduce erosion and maximise water penetration rather than running off. In the Western Australian Goldfields, mining waste can contain pyrite, which when exposed to water and oxygen increases soil acidity, can contain hypersaline water, may contain concentrations of toxic chemicals or may be hard rock, all of which provide challenges for mine site rehabilitation planners and extra difficulties in achieving near-natural, functional ecosystems as final outcomes for rehabilitated areas.

Typically, once the geophysical structure for a waste dump is complete, it is seeded and left for nature to take its course. Microbial organisms are generally brought onto the site in the soils, and by wind and water; invertebrates colonise the waste dump from adjacent areas; and vertebrate communities are generally the last to move onto waste dumps because of their need for complex vegetation assemblages and invertebrate prey. It is for this reason that vertebrates provide a very useful bio-indicator of the success of waste dump rehabilitation programs in creating near natural, self-sustaining, functional ecosystems.

We report here on the relative abundance of amphibians, reptiles and mammals on five waste dumps in the early successional stages (3-14 years) in the mined area around Ora Banda in Western Australia and compare these data with species richness and abundance in adjacent undisturbed areas.

\section{METHODOLOGY}

\section{$2.1 \quad$ Study Site}

We sampled the small trappable vertebrate fauna on five rehabilitated mine-site waste dumps and the adjacent undisturbed areas in the gold mining region of Ora Banda $\left(30^{\circ} 27^{\prime} \mathrm{S}, 121^{\circ} 4^{\prime} \mathrm{E}\right.$; approximately 50 $\mathrm{km}$ north of Kalgoorlie, WA; Figure 1). Ora Banda lies on Archaen granites that underlie lateritic gravel soils. The vegetation was heterogenous, ranging from Eucalypt-Casuarina-Mulga woodlands interspersed with Acacia, to sparsely distributed spinifex (Triodia spp.) and shrubs (Acacia spp.) to dense shrubs (Acacia spp., Atriplex spp., Allocasuarina spp.). Vegetation on each of the rehabilitated waste dumps varied appreciably and was not the same as in the adjacent undisturbed areas.

When we commenced this project in June 2000, rehabilitation had been in place at Wendy Gully waste dump for 3 years, at Palace waste dump for 4 years, at Rose waste dump for 7 years, at Gimlet waste dump for 8 years, and at Golden Arrow waste dump there was a two-stage rehabilitation. Rehabilitation on the top of Golden Arrow was 5 years old and the sides were 9 years old. We presumed the primary source of colonising vertebrate species onto waste dumps was from the adjacent undisturbed areas. Reptiles, amphibians and 
mammals were present on all waste dumps, but not all the species in the adjacent undisturbed areas were present.

\section{Layout of pit-traps in undisturbed areas}

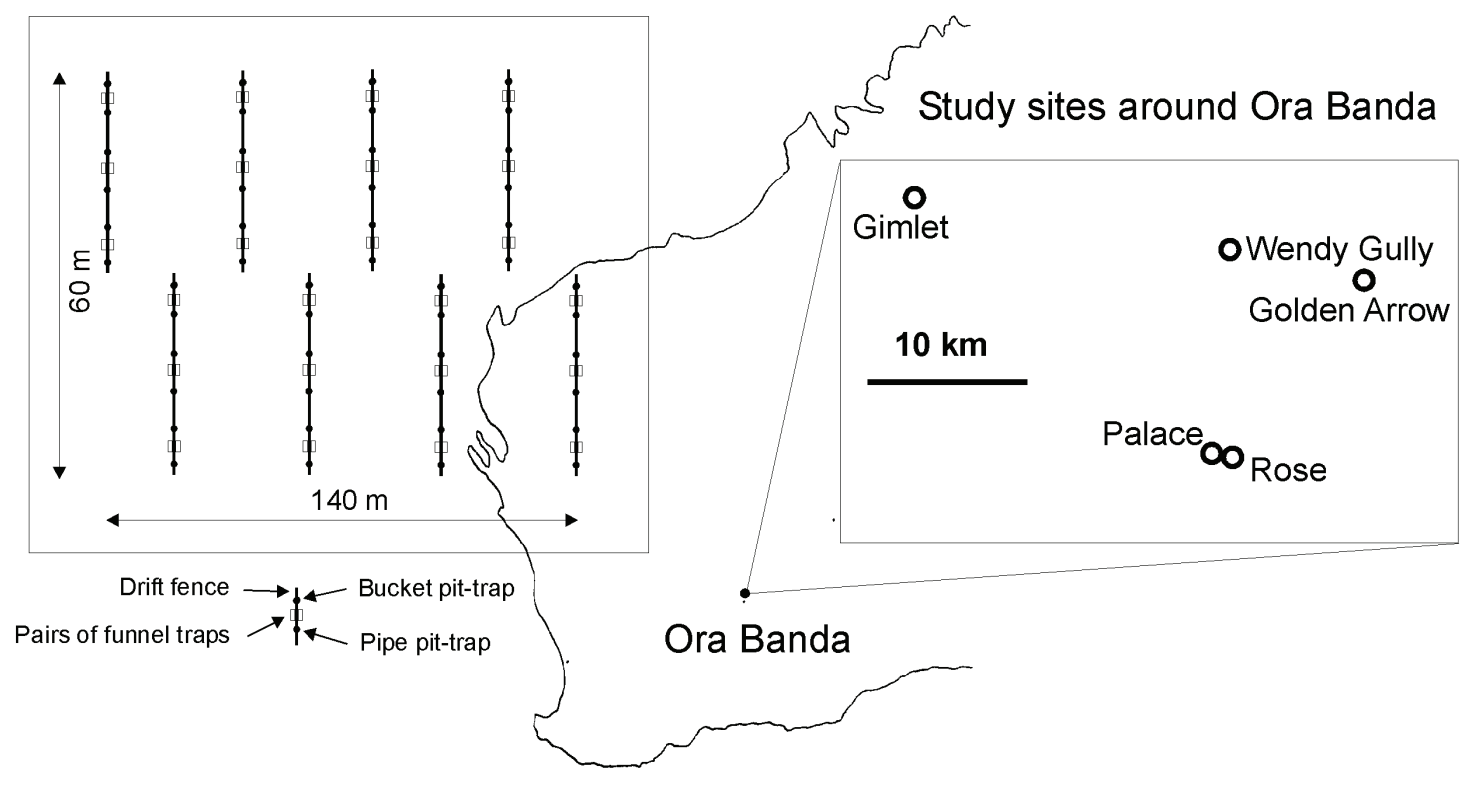

Figure $1 \quad$ Location of study sites and layout for traps in the undisturbed areas

\subsection{Data Collection Strategies}

We trapped small mammals, reptiles and frogs on rehabilitated waste dumps and in the adjacent undisturbed areas during January in 2001, 2002, 2003, 2004 and 2006. Four rehabilitated mine site waste dumps (Gimlet, Palace, Rose and Wendy Gully) and the adjacent undisturbed areas were surveyed on all five occasions. Pittraps were dug in at Golden Arrow in June 2001 and were first sampled in January 2002.

Pit-traps were used during all surveys. Each trapping line consisted of three alternating $20 \mathrm{~L}$ PVC buckets and $150 \mathrm{~mm}$ PVC pipes (600 $\mathrm{mm}$ deep) dug into the ground along $30 \mathrm{~m}$ fly-wire drift fences that were approximately $250 \mathrm{~mm}$ high. In the undisturbed areas adjacent to each waste dump we installed eight lines of six pit-traps (Figure 1). For rehabilitated areas, there were six lines of six pit-traps on the slope of the dump (batters) and another six lines of six pit-traps on the top of the dump. During the last two surveys (January 2004 and 2006), three pairs of funnel-traps were evenly spaced along each drift fence between pit-traps. Funnel-traps were made of netting with ends $170 \times 170 \mathrm{~mm}$ and a length of $750 \mathrm{~mm}$, with an opening of about $50 \mathrm{~mm}$ diameter at each end. A pair of funnel-traps was placed next to each other on either side of the drift fence (Figure 1), and because a pair have about the same propensity to catch animals moving along the drift fence as a pit-trap (i.e. their catching distance either side of the drift fence was very similar), a pair of funnel traps was counted as a single trapping unit, equivalent to a bucket or pipe pit-trap. For the first three surveys, each pit-trap was open for seven days and cleared daily. For the surveys in January 2004 and 2006, each trap was left open for 14 days and cleared daily. Each capture was identified, sexed (where possible), weighed and measured. Most amphibians, reptiles and mammals were released near their point of capture. A few individuals were lodged with the Western Australian Museum as voucher specimens.

\subsection{Data Analysis}

This analysis compares both species richness and relative abundance of reptiles, amphibians and mammals on waste dumps with that in the adjacent undisturbed areas. All capture rates were converted to captures per 100 trap-nights to accommodate the higher trapping effort on waste dumps compared with the undisturbed 
areas. Mammals were very seldom caught in funnel traps, therefore catch rates for mammals were based on pit-trap nights only, whereas for reptiles and amphibians, the trapping rate incorporates both pit-traps and funnel traps.

ANOVA was used to compare the catch rates for individual reptiles and mammals in rehabilitated areas with adjacent undisturbed areas among sites and years. $t$-tests were used to compare catch rates for individual reptiles and mammals on a yearly basis.

As we wished to demonstrate differences among catch rates for various taxa on rehabilitated waste dumps with the adjacent undisturbed areas, and as catch rates for different species varied among years as the succession process progressed, we selected the data for January 2006 for this analysis. $t$-tests were used to compare these differences. For all analyses, we set $\alpha=0.05$ as our confidence limits.

\section{RESULTS}

Overall there was no significant difference in the number of species of mammals caught on rehabilitated waste dumps and the adjacent undisturbed areas $\left(F_{1,38}=1.46, P=0.235\right)$ over the five sampling periods (Table 1). However, for reptiles the number of species caught on rehabilitated waste dumps was significantly less $\left(F_{1,38}=88.5, P<0.001\right)$ than were caught in the undisturbed areas for all sites and years (Table 1$)$.

Table 1 Number of species of mammals and reptiles caught on waste dumps and the adjacent undisturbed areas during surveys in January 2001, 2002, 2003, 2004 and 2006

\begin{tabular}{|c|c|c|c|c|c|c|c|c|c|c|c|c|}
\hline & & 这 & 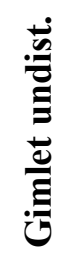 & 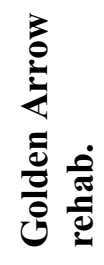 & 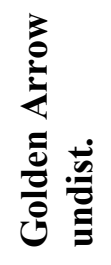 & 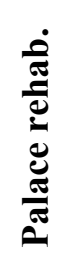 & 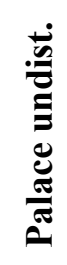 & 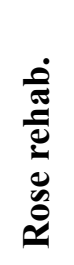 & 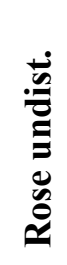 & 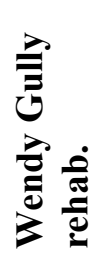 & 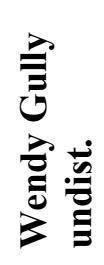 & 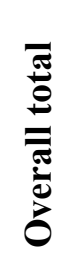 \\
\hline \multirow[t]{5}{*}{ Mammals } & 2001 & 4 & 2 & & & 3 & 4 & 2 & 4 & 2 & 2 & 6 \\
\hline & 2002 & 3 & 1 & 7 & 5 & 3 & 2 & 5 & 2 & 6 & 4 & 8 \\
\hline & 2003 & 4 & 4 & 5 & 4 & 2 & 4 & 5 & 4 & 4 & 2 & 8 \\
\hline & 2004 & 3 & 2 & 5 & 5 & 4 & 4 & 3 & 7 & 4 & 4 & 7 \\
\hline & 2006 & 4 & 3 & 6 & 4 & 4 & 4 & 5 & 4 & 4 & 6 & 7 \\
\hline \multirow[t]{5}{*}{ Reptiles } & 2001 & 5 & 16 & & & 7 & 17 & 9 & 19 & 5 & 19 & 36 \\
\hline & 2002 & 6 & 19 & 5 & 11 & 4 & 17 & 8 & 12 & 8 & 13 & 35 \\
\hline & 2003 & 4 & 8 & 3 & 15 & 3 & 7 & 3 & 10 & 9 & 9 & 26 \\
\hline & 2004 & 9 & 20 & 11 & 23 & 10 & 20 & 18 & 21 & 9 & 23 & 44 \\
\hline & 2006 & 14 & 28 & 15 & 21 & 12 & 18 & 17 & 17 & 18 & 24 & 44 \\
\hline
\end{tabular}

There was a significant difference in the catch rates for mammals $\left(F_{1,38}=24.1, \mathrm{P}<0.05\right)$ and reptiles $\left(F_{1,38}=\right.$ $37.6, \mathrm{P}<0.05)$ on the rehabilitated waste dumps compared with the adjacent undisturbed areas. For all years, 
the catch rate of mammals on waste dumps was significantly higher than for the adjacent undisturbed areas using a one-tailed $t$-test $(2001, P=0.047 ; 2002, P=0.040 ; 2003, P=0.018 ; 2004, P=0.047 ; 2006, P=$ 0.005). For reptiles, catch rates were significantly higher in the undisturbed areas than on waste dumps during the first four surveys using a one-tailed $t$-test $(2001, P=0.007 ; 2002, P<0001 ; 2003, P=0.022$; $2004, P=0.017 ; 2006, P=0.262$ ), and there was no difference in January 2006. Previous research suggested a hypothesis that reptile abundance would be higher in undisturbed areas than rehabilitated areas during early succession, thus the use of a one-tailed $t$-test.

Ningaui sp. were caught in low numbers over the five January surveys. Two Kultarr (Antechinomys laniger) were caught, one each on the rehabilitated waste dumps at Rose and Wendy Gully. As a consequence it was difficult to draw conclusions about their ability to colonise rehabilitated waste dumps.

For January 2006, the catch rates for Mus musculus $(P=0.006)$ and Sminthopsis crassicaudata $(P=0.014)$ were significantly higher in the rehabilitated areas than the undisturbed areas, but for Sminthopsis dolicura $(P=0.037)$ the catch rate was significantly higher in the undisturbed areas compared with the rehabilitated areas using a one-tailed $t$-test. Previous research suggested a hypothesis that some Sminthopsis and Mus abundance would be higher in rehabilitated areas than undisturbed areas during early succession, thus the use of a one-tailed $t$-test. There was no difference in the catch rates for Pseudomys hermannsburgensis and $P$. bolami between waste dumps and adjacent undisturbed areas, although this result may reflect the small sample (Appendix 1).

The catch rates for pygopods $(P=0.001)$ and skinks $(P=0.005)$ were significantly higher in the undisturbed areas than the rehabilitated areas, whereas the catch rate for geckos was significantly higher in the rehabilitated areas than the adjacent undisturbed areas $(P=0.031)$ using a one-tailed $t$-test. There were no significant differences for dragon lizards, elapid snakes, blind snakes and goannas between the catch rates on waste dumps and the adjacent undisturbed areas. Of those reptile species found on all sites, Pogona minor $(P$ $=0.036)$, Heteronotia binoei $(P=0.002)$ and Underwoodasauris milii $(P=0.004)$ were caught more often on rehabilitated waste dumps than in undisturbed areas, whereas Diplodactylus pulcher $(P=0.002)$ and $D$. maini $(P=0.020)$ were caught more often in undisturbed areas than on rehabilitated waste dumps. There was no significant difference in catch rates for Varanus gouldii, Gehyra variegata and Diplodactylus granariensis on waste dumps and the adjacent undisturbed areas. A large number of reptiles were caught in relatively low numbers, and these were predominantly caught in undisturbed areas (see Appendix 1 for 2006 data).

Pseudophryne occidentalis was found at all sites, and in large numbers on Gimlet waste dump (242 from 2001 to 2006) compared with the adjacent undisturbed area (64 from 2001 to 2006). Neobatrachus sp. (sutor and kunapalari) were caught only after the first couple of days of heavy rain, and were present on all sites except Wendy Gully (unpublished data), but generally in lower numbers on waste dumps than the adjacent undisturbed areas.

\section{DISCUSSION}

Topography, soils and vegetation on all five waste dumps varied and rehabilitation had been underway for between 3-14 years. All waste dumps were in an early stage of establishing natural ecosystems. Vegetation cover on waste dumps varied both within and among waste dumps. The slopes on sections of some waste dumps had been heavily eroded, and nearby, there was evidence of long-term stability and substantial vegetation cover. This variability in rehabilitation inevitably results in considerable variability in the vertebrate assemblages on these waste dumps. Therefore the faunal assemblages reported here would not be uniform across each of the waste dumps.

\subsection{Mammals}

All of the small mammal species in the adjacent undisturbed areas had moved onto the rehabilitated waste dumps. Twigg et al. (1989) reported that M. musculus was the first of the mammals to return to rehabilitated sand mining areas in the Myall Lakes National Park, followed by Pseudomys novaehollandiae and Sminthopsis murina. Although our time frame is short, species from the same genera were also present on some rehabilitated waste dumps during our January 2001 survey. Sminthopsis crassicauda and M. musculus were mostly caught on waste dumps and P. bolami was caught in low numbers across both habitat types. 
Catch rates varied appreciably for Cercartetus concinnus among sites, habitats and survey periods and it is difficult to understand the pattern. However, they were present in low numbers in January 2001 on the Gimlet waste dump and the adjacent undisturbed areas, and the undisturbed areas at Palace and Rose. In January 2002 they were caught on all five waste dumps in low numbers. Sminthopsis dolicura were not caught on waste dumps in January 2001, but were caught on all dumps except Gimlet in 2002. The general pattern remained unchanged through to January 2006 with significantly more $M$. musculus and $S$. crassicaudata being caught on the rehabilitated waste dumps and more $S$. dolicura being caught in the adjacent undisturbed areas.

House mice (M. musculus) have a recognised capacity to exploit a diverse range of habitats. The Fat-tailed Dunnart (S. crassicaudata) is well adapted to arid and semi-arid habitats and is often the only small mammal found in highly disturbed landscapes in the Western Australian wheatbelt. Our data suggests that these are two of the earliest colonisers probably because of their adaptability to a variety of habitats, and that they can flourish in disturbed areas, perhaps assisted by low levels of predation. Two Ningaui sp. were caught around Ora Banda; N. yvonneae and N. ridei, but it is difficult to confidently distinguish between these two species in the field. Ningaui sp. were caught in low numbers on and off waste dumps, so it is difficult to speculate on their ability to establish populations on rehabilitated waste dumps. Cercartetus concinnus is probably also one of the early colonisers if the habitat is suitable, but variability in catch rates among sites and seasons, made it difficult to draw strong conclusions. There was no consistent difference in the catch rates for $P$. bolami and $P$. hermannsburgensis on and off waste dumps and their numbers appeared to fluctuate on a seasonal basis (unpub. data), suggesting a much larger dataset maybe required to understand the colonising ability of these species.

Overall, these data suggest that other than Ningaui sp. and to a less extent $P$. hermannsburgensis, for which we have limited data, the other common small mammals found around Ora Banda colonise rehabilitated waste dumps within the first three to five years of the development of vegetation. Mus musculus and $S$. crassicaudata seem to flourish, perhaps because of limited competition for resources and reduced predation pressures. Only after we commenced using funnel traps in January 2004 did we start catching the large elapid snakes on waste dumps, so we are unsure whether they were present in the earlier years and predating on the smaller mammals and regulating their population numbers, or whether they were absent enabling the population of smaller mammals to increase unchecked by heavy predation.

\subsection{Amphibians}

Three frog species were caught during January surveys following local thunderstorms. Neobatrachus sutor and $N$. kunapalari were only active and trapped after the first couple of days of heavy rain, whereas $P$. occidentalis was surface active for longer periods (Thompson et al., 2003). Pseudophryne occidentalis was caught in significantly higher numbers on Gimlet rehabilitated waste dump than the adjacent undisturbed area, and in lower numbers on Palace waste dump than the adjacent undisturbed area. Neobatrachus sp. were caught both on and off waste dumps, but generally in higher numbers in the undisturbed areas. More comprehensive sampling immediately after heavy rain at various times during the year is required to develop a good appreciation of the extent to which arid-adapted frogs move onto waste dumps. However, our preliminary data indicate that $P$. occidentalis will colonise waste dumps in large numbers where surface water can accumulate and where there are rocks and crevices under which they can retreat to avoid desiccation. Neobatrachus sp. are early but slow colonisers of rehabilitated waste dumps.

\subsection{Reptiles}

In the first four years of surveying the number of reptiles caught in undisturbed areas was much higher than on waste dumps. By January 2006 this difference had disappeared, indicating the number of reptiles on waste dumps had increased significantly. However, the composition of the reptile assemblage on waste dumps was still appreciably different to that in the adjacent undisturbed areas. Generally waste dumps contained fewer species (Table 1) but more individuals for these species (Appendix 1). 


\subsubsection{Snakes}

Large snakes can only be adequately trapped in funnel traps, as they easily climb in and out of most pit-traps. Our data for 2004 and 2006 indicate that Pseudechis australis (Mulga snake) and Demansia psammophis (Yellow-faced Whipsnake) were present on waste dumps. In many ways, waste dumps provide a suitable habitat for these top-of-the-food-chain predators, as there are many places to quickly retreat from danger or solar radiation but they are capable of searching the many cracks and crevices found on waste dumps where small mammals and reptiles hide. Large elapids were encountered in low numbers on waste dumps and the adjacent undisturbed areas, indicating that they will move into early stage rehabilitated areas in search of prey.

Although blind snakes were generally found on waste dumps, they were less plentiful than in undisturbed areas, suggesting that they are early colonisers but are slow to increase their numbers.

\subsubsection{Dragon lizards}

Pogona minor was more prevalent on rehabilitated waste dumps than the adjacent undisturbed areas. Thompson and Thompson (2003) suggested that $P$. minor was well adapted to early stage rehabilitated areas as it forages-widely, will readily cross a variety of terrains, including unvegetated areas, will climb slopes, has a diet of invertebrates and vegetable matter, and forages in dense low shrubs such as chenopods, which are often the most abundant shrub on waste dumps in the Goldfields. Most of the other agamids were caught in appreciably higher numbers in the adjacent undisturbed areas, which meant that overall, there was little difference in the number of agamids caught in rehabilitated waste dumps and the adjacent undisturbed areas.

\subsubsection{Geckos and legless lizards}

Underwoodisauris milii and $H$. binoei were consistently caught in higher numbers on waste dumps than the adjacent undisturbed areas. Both of these geckos are also found in other disturbed habitats in the Goldfields (e.g. rubbish tips). It is therefore evident that these species flourish in disturbed habitats and are probably two of the earliest reptile colonisers along with $P$. minor onto rehabilitated areas. In contrast, the terrestrial $D$. pulcher and D. maini, which were found on all sites but mostly in the undisturbed areas, have a preference for mircohabitats that contain relatively high levels of leaf litter which are not always available on waste dumps. Gehyra variegata and D. granariensis were found at all sites, and were caught in relatively high numbers on both waste dumps and undisturbed areas. These two species are generalists that seem to adapt well to developing habitats, but follow the early colonisers, so growth in their numbers is limited by competition with the species that arrived earlier. Diplodactylus maini was first caught on a waste dump during 2004 and Rhynchoedura ornata was first caught on a waste dump in 2006. Our unpublished survey data for these sites in 2000, 2001 and 2002 collected at other times of the year (e.g. September, December and April) confirm the lack of captures during this period. Rhynchoedura ornata is a widely-foraging, terrestrial, termite eating specialist. Given that few waste dumps contain sufficient decaying material to support colonies of termites, it is likely this species will be a late coloniser unless substantial quantities of vegetation are spread over the surface of waste dumps during the construction phase. Diplodactylus maini is mostly found in areas with substantial leaf litter in undisturbed areas, habitat that is not common on waste dumps. Egernia inornata and E. formosa live in colonies and appear to remain within defined activity areas, and were never caught on waste dumps. We interpret these data to indicate that there are a few gecko species that are spatially mobile and have a preference for disturbed sites, and are among the first group of small terrestrial vertebrates to colonise rehabilitated waste dumps. There are others that have specific microhabitat requirements that will be slow to colonise waste dumps and probably will not appear until specific niches have become available.

Although significantly more pygopods were caught in the undisturbed areas than on waste dumps, catch rates for legless lizards were generally too low to draw any reasonable conclusions.

\subsubsection{Skinks}

In contrast with geckos, significantly more skinks were caught in the undisturbed areas than on waste dumps, and there was no particular species that went against this trend (Appendix 1). Fossorial skinks like Hemiergis initialis, Lerista muelleri and Lerista picturata were seldom caught on waste dumps, possibly because the 
soils were not suitable, but Eremiascincus richardsoni, another sand swimmer, was occasionally caught on waste dumps. The large, slow moving Tiliqua occipitalis was only caught in low numbers and only in the undisturbed areas, but $T$. rugosa was caught in both habitats. These two species are ecologically similar and sympatric, so the reason for the difference is unknown. These species are generally difficult to catch in pittraps and seldom caught in funnel traps. Trap-wariness might mean that they were not being adequately sampled.

\subsubsection{Goannas}

Varanus caudolineatus and $V$. tristis are both essentially arboreal, but forage for prey on the ground. Varanus caudolineatus is almost always found in treed habitats, as it retreats to the hollows of trees and logs, as does $V$. tristis, albeit larger hollows (Thompson, 1993; Thompson et al., 1999). It is therefore unlikely that these species will be found on waste dumps without trees. In comparison, Varanus gouldii is a larger, terrestrial, wide-foraging goanna (Thompson, 1992; 1994) and was caught in equal numbers on waste dumps and the adjacent undisturbed areas.

\section{CONCLUSIONS AND IMPLICATIONS FOR REHABILITATION PLANNING}

All of the common small mammals present in the undisturbed areas were present on rehabilitated waste dumps in the first couple of years after they were vegetated, and some species were present in higher numbers on waste dumps than in the adjacent undisturbed areas, possibly due to reduced competition and predation. In contrast, only a few of the available species of reptiles were among the early colonisers, while the vast majority were represented in low numbers during the first 3-14 years of development and a small number will probably not be found on waste dumps for many years. Reptiles with a generalist diet, that forage widely, that are comfortable in unvegetated spaces or prefer disturbed areas will be among the first to colonise waste dumps.

Underwoodisauris milii, H. binoei, P. minor, M. musculus and S. crassicaudata are probably among the first species to move onto rehabilitated waste dumps. Pogona minor, M. musculus and S. crassicaudata have the reproductive capacity to increase their numbers rapidly as each can have a clutch or litter of 4 to 10 , multiple times each year, whereas $U$. milii and $H$. binoei are restricted to two eggs per clutch, and it is not known if they have multiple clutches in a year. Their spatial mobility and plastic habitat requirements means that they are able to exploit a developing rehabilitated waste dump before many other species arrive and become established.

Reptiles with specific habitat or dietary requirements are only likely to colonise waste dumps when their requirements are met. For example, species that retreat to trees (e.g. Egernia depressa, V. caudolineatus) or are termite specialists (e.g. D. pulcher and $R$. ornata) will only move onto to waste dumps when vegetation, logs and tree hollows are available. Fossorial species such as Brachyurophis semifasciata and Lerista pictura require a surface substrate into which they can burrow or a dense cover of leaf litter, and these conditions are seldom found on waste dumps during the early years of a rehabilitation program. These species are therefore likely to be late colonisers. Other reptile species may have poor dispersal capabilities (e.g. those that live in colonies) or only move into new areas when forced out of their existing activity areas. In contrast, species that forage in, under or around chenopod shrubs (e.g. P. minor, Strophurus assimilis, D. graneriensis) and are spatially mobile will readily colonise rehabilitated waste dumps once the chenopods have become established. Patterns of recolonisation reported here are similar to those reported in other habitat types. For example, Nichols and Nichols (2003) describe a similar pattern of generalist foraging mammals recolonising rapidly, whereas small predators took longer, feral mice were initially abundant and then declines, reptiles took longer than mammals to move into rehabilitated Jarrah forests.

We would argue that the primary objective for most rehabilitated mine site waste dumps should be the creation of self-sustaining, functional ecosystems that are similar to those found in the adjacent areas. Creating the topography, soils and vegetation to support natural ecosystems will be a challenge for most waste dumps in the Goldfields as they are generally large mounds that rise above the surrounding area. High, steep-sided waste dumps with a small footprint incur lower environmental bonds and are therefore the preferred option for mining companies. These structures often also have a substrate that is different to the 
surrounding soils, are difficult to vegetate and prone to erosion, and are therefore difficult to establish ecosystems that are similar to the adjacent areas. Perhaps waste dumps that are lower, have less steep sides, but with a slightly larger footprint would be more amenable to establishing ecosystems similar to those in the surrounding areas. This change in the structure of waste dumps is only likely to occur after a change in government policy in the method of calculating environmental bonds.

Spreading vegetation (including logs and dead trees) over the surface of waste dumps during the construction phase increases the range of fauna habitats and probably reduces the potential for gully erosion. Using seed mixes that will result in vegetation assemblages that are similar to the adjacent habitat will provide niches for habitat specialists. Minimising the cleared aprons around the perimeter of waste dumps will improve the connectivity between the rehabilitated area and the adjacent undisturbed area, increasing the propensity for small vertebrates to move into the rehabilitated areas.

Rehabilitation guidelines issued by government agencies need to focus much more on the creation of functional ecosystems using bio-indicators such as reptiles and mammals, and perhaps invertebrates. These classes of bio-indicators provide a better indication of the holistic success of rehabilitation programs than some of the abiotic ones promoted by the Environmental Protection Authority (2006). This is not to diminish the usefulness of indictors such as Ecosystem Functional Analysis (EFA) as they are useful tools in assessing stability and nutrient recycling which are important prerequisites to establishing functional ecosystems.

\section{ACKNOWLEDGEMENTS}

This project has been financially supported by Barrick Kanowa, OMG Nickel Pty Ltd and ATA Environmental, for which we are very appreciative. All fauna surveys were conducted under licenses issued by the Department of Conservation and Land Management and animal ethics approval from Edith Cowan University.

\section{REFERENCES}

Environmental Protection Authority (2006) Guidance for assessment of environmental factors (in accordance with the Environmental Protection Act 1986) Rehabilitation of terrestrial ecosystems, No. 6. Environmental Protection Authority, Perth.

Nichols, O.G. and Nichols, F.M. (2003) Long-term trends in faunal recolonization after bauxite mining in the Jarrah forest of southewestern Australia. Restoration Ecology, 11, pp. 261-272.

Thompson, G. (1992) Daily distance travelled and foraging areas of Varanus gouldii (Reptilia: Varanidae) in an urban environment. Wildlife Research, 19, pp. 743-753.

Thompson, G. (1993) Daily movement patterns and habitat preferences of Varanus caudolineatus (Reptilia: Varanidae). Wildlife Research, 20, pp. 227-231.

Thompson, G.G. (1994) Activity area during the breeding season of Varanus gouldii (Reptilia:Varanidae) in an urban environment. Wildlife Research 21, pp. 633-641.

Thompson, G.G., de Boer. M. and Pianka, E.R. (1999) Activity areas and daily movements of an arboreal monitor lizard, Varanus tristis, (Squamata: Varanidae) during the breeding season. Australian Journal of Ecology, 24, pp. 117-122.

Thompson, G.G., Thompson, S.A. and Fraser, J.L. (2003) Surface activity of arid-adapted frogs. Journal of the Royal Society of Western Australia, 86, pp. 115-116.

Thompson, S.A. and Thompson, G.G. (2003) The western bearded dragon, Pogona minor (Squamata: Agamidae): An early lizard coloniser of rehabilitated areas. Journal of the Royal Society of Western Australia 86, pp. 1-6.

Twigg, L.E., Fox, B.J. and Jia, L. (1989) The modified primary succession following sand mining: A validation of the use of chronosequence analysis. Australian Journal of Ecology, 14, pp. 441-447. 


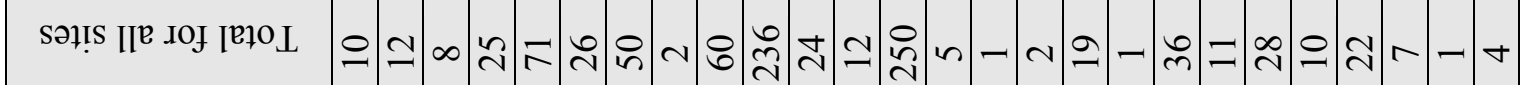

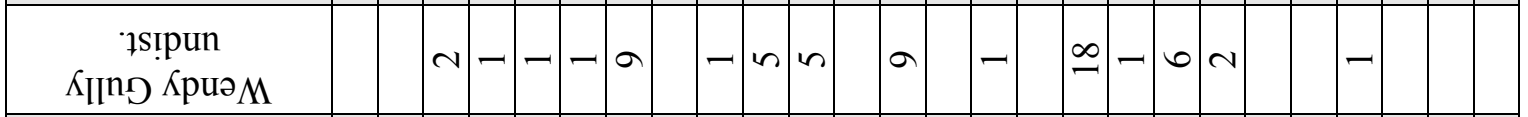

\begin{tabular}{|c|c|c|c|c|c|c|c|c|c|c|c|c|c|c|c|c|c|}
\hline 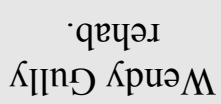 & - & & -1 & 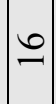 & $-\mid \nabla$ & $\sim$ & 于 & 6 & $\bar{m}$ & & - & & $m$ & & & & \\
\hline 'łs!̣pun əsoy & $m$ & $\nabla$ & & 으 & $r-$ & $\infty$ & -4 & $\approx$ & $m$ & - & & - & & a & $\vec{\sim}$ & & 一 \\
\hline ‘qчәә әsoy & & $\mathrm{N}$ & $N$ & $\Xi$ & $m$ & 0 & | & -- & రु & & & & -0 & & & & - \\
\hline
\end{tabular}

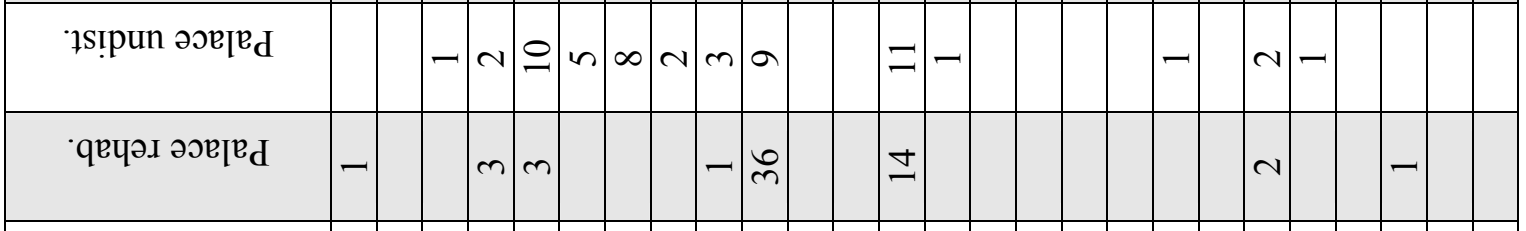

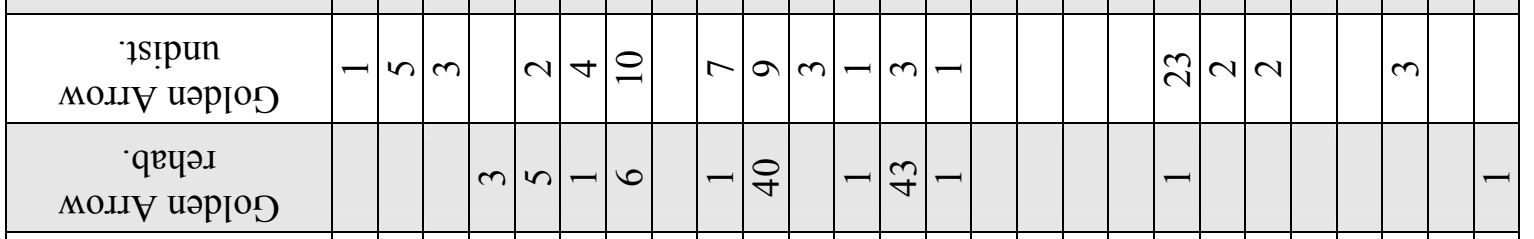

\begin{tabular}{|c|c|c|c|c|c|c|c|c|c|c|c|c|c|c|c|c|c|}
\hline 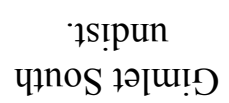 & $\nabla$ & & $-1-$ & $\checkmark$ & 0 & $m$ & $n$ & 0 & $N$ & r & -1 & $N$ & $\nabla$ & & 0 & 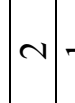 & -- \\
\hline 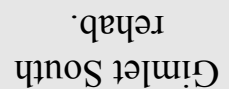 & & & 6 & 0 & - & & & $\stackrel{\infty}{\sim}$ & & $\widehat{6}$ & & & & & $\nabla$ & - & \\
\hline
\end{tabular}

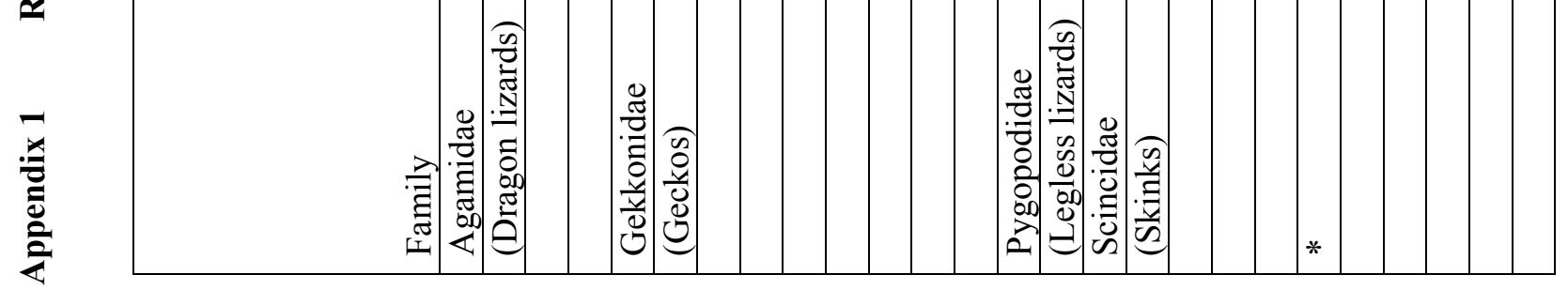




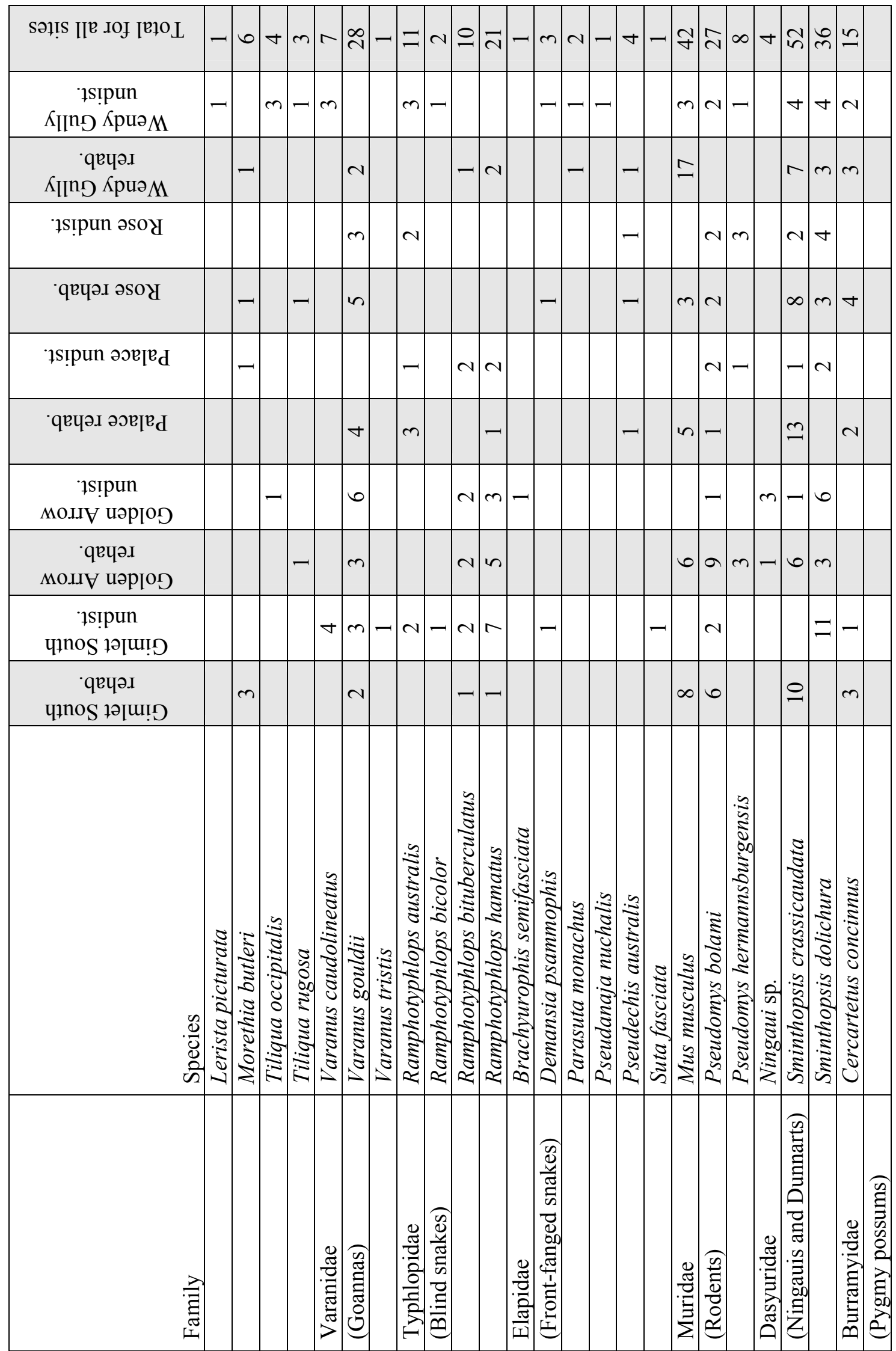

